\title{
A Study of an Evaluation Model on Manufacturing Execution System in Paper-making Enterprises
}

\author{
Zhihong Xu \\ Key Lab for Paper Science and Technology of Ministry of Education \\ Shandong Institute of Light Industry \\ Shandong 250353, China \\ E-mail:xzh1385@163.com \\ Feng Huang \\ The State Key Laboratory for Microbial Technology \\ Shandong University, Shandong 250100, China \\ Jiachuan Chen \& Guihua Yang \\ Key Lab for Paper Science and Technology of Ministry of Education \\ Shandong Institute of Light Industry \\ Shandong 250353, China
}

\begin{abstract}
Manufacturing execution system (MES) is a production management technology and real-time information system which lies between the enterprise upper layer (ERP) and the bottom layer (PLC/DCS) and faces to workshop layer. MES's concept, its functional model and its important status in the manufacture industry are introduced in this article. Based on the production practice in Kunshan Banknote Paper Mill, an evaluation model of EMS is set up. The model also has a certain reference value to the construction of management information system (MIS) for the relative industries.
\end{abstract}

Keywords: Pulp and paper industry, Manufacturing execution system, Furzzy evaluating method

\section{Introduction}

The construction of informationization has made considerable progress with years of development in domestic paper industry. Large and medium-sized paper-making enterprises has widely adopted Enterprise Resource Planning (ERP) for enterprise production planning management and Process Control System (PCS) for control of paper production process. However, it lacks effective unity and communication of model and information between the production planning management of upper layer and the process control of bottom layer, which cause unsuccessful performance of specific business functions in the control layer in time, bad visibility of production information such as supplies, equipment, product quality and order information etc, as well as difficulties of information communication. In response to this question, Manufacturing Execution System (MES) emerged.

MES is an information system in factory layer permanently between planning system of enterprise leadership and direct industrial control system of production process. It provides data and information of all the resources of the production process like personnel, equipment, materials, tools and customer requirements for operators and managers in a current perspective. And it focuses on improving the manufacturing process using information technology. On the one hand, MES eliminates the information divide between ERP and PCS, so that operators and managers can grasp the actual situation of production timely and accurately in the planning process, and be well guided to formulate practical plans in production process at the same time; on the other hand, operators and managers can track the status information of products in the production process in time using MES so as to control inventory effectively, while the consumer can know the implementation of order before delivery.

\section{Characteristics of paper making industry and the applications of MES}

As a part of process industry, the characteristics of pulp and paper industry are as follows: the flow of materiel and energy is running during the production process, and the producing technics and methods are complex, however, the 
process flow and the products are relatively stable; production can be more flexible in some measure via adjusting the technological parameter online; production process involves a variety of physical and chemical process, so it has complex mechanism and big quantity of data information, and is very difficult to deal with; it has a nice producing rhythmicity and requires better continuity and balance, as well as highly requirement in automatization of the production process control and device control; the management and decision-making of investment, update, rebuilding and servicing of the devices are quite intricate, at the same time, peculiar requirements of storage and contamination are needed(Liu, Tieming, Xong, Gang, Shen, Judong, et al, 2000)(Li, Minghui, Wang, Mengxiao, Hu, Nanjiang, 2006).

(1) characteristics and requirements of integrated management

Integrated management has functions of producing planning and attempering, which can coordinate every working procedure range from raw material, energy supply, manufacture to shipment, in order to expediting the circulation of raw material and finished product, and to increase the liquidity.

(2) characteristics and requirements of production control

Since the production of pulp and paper industry is continuous, emphasizing the integrity of production process becomes very important, which needs us to consider different devices and production processes as a whole. Terrible conditions involving high temperature, dampness, vibration, and serious erosion in pulp and paper production process can lead to serious equipment depreciation. Some of the key production equipments need regular inspection and maintenance, including preventive maintenance and on-line diagnoses. Variables of pulp and paper production process variables related strongly to each other as well as serious coupling, which put forward higher requirements of fault diagnosis technology.

(3) characteristics and design requirements of cleaner production

Paper industry is an important basic industry of the national economy providing social production and living of necessary various paper products. At the same time, it is concerned from all sides because of its substantial energy consumption, water consumption, as well as a direct impact on the environment. Paper-making enterprises should strengthen its information technology of information collection, treatment and decision-making functions in terms of saving energy, reducing pollution emissions and comprehensive utilization of resources.

\section{MES evaluation model}

\subsection{Evaluation model index system}

MES evaluation requires a variety of indicators(J. Sarkis and R.P. Sundarraj, 2005)( J.S.Dyer, 1999)(S.Schenkerman, 1999). The quality evaluation index setting is directly related to the quality or success of the MES performance evaluation. Choosing the correct and reasonable performance evaluation indicators can assist businesses and MES to optimize the allocation of resources, to improve system performance, to propose measures for improvement. Therefore, to determination the performance evaluation indicators should follow the following principles:

(1)Systematicness: It must reflect the comprehensive situation of the production process, and grasp the main factors affecting the system.

(2)Levels: A complex process at different levels is decomposed into multiple sub-processes, the evaluation indicators of which are different of the general, and the same level indicators should be given appropriate weight.

(3)Mensurability: The meaning of indicators is clear, and the data needed are facilitated to collect and analyse.

(4) A combination of qualitative and quantitative: The value of quantitative indicators can be calculated in accordance with the corresponding formula; while the quantifiable results of qualitative indicators are evaluated based on the evaluation criteria and the actual situation, as well as personal experience by the relevant staff, and qualitative indicators can make up for disadvantage that some indicators are currently unable to obtain accurate data.

(5) Relativity: Various indicators should reflect the system performance from different angles. Selection of different indicators like that to do evaluation can master the operation of the system much completely.

When designing index system, we drew on a number of other studies in this area. For example, we studied how to assess the core competitiveness of paper-making enterprises using AHP from Sun Chunlei(Sun, Chunlei, 2004), and evaluated the implementation capacity of information of manufacturing sector using fuzzy evaluation method and AHP from Qi Ershi, Li Gang and Song Chunhua(Qi, Ershi, Li, Gang, Song, Ninghua, 2006).

The emphases of our evaluation model are to investigate the capacity of improving performance of MES for paper production. And then we got the following model:

According to the actual situation of enterprises, we broke all the relevant factors down into several levels from top to bottom in accordance with the different properties, and set up a three-tier model structure.

Target layer: That is, production performance evaluation and analysis of paper-making enterprise MES. 
Criteria layer: Various influencing factors of the implementation of paper-making enterprise resource planning and production processes, which we summed up in five areas: integration factors; production factors; quality factor; resource utilization factors; cleaner production factors.

Indicator layer: every specific indicators element impacting the criteria layer.

The indicator system is shown in Figure 1.

The four indicators of cleaner production factors in this model are "lower pollution \& waste reduction", "waste utilization", "pollution control" and "energy consumption", and the data can be obtained in accordance with the evaluation system of Development and Reform Commission.

In all the indicators, integration factors and cleaner production factors are qualitative ones, and such indicators obtain data by investigation or expert scoring method; while the other three indicators are quantitative, and such indicators obtain data by current statistics report or equipment real-time production data.

\subsection{Fuzzy evaluation method}

We adopt a fuzzy evaluation method to calculate. Readers can access the relevant literature to know the algorithm ( $\mathrm{Li}$, Enke, Ma, Yuxiang, 2000)( Tao, Qing, Zheng, Wentang, 2002). Because of space limitations we only write its basic calculation steps without detailed introduction: (1) to set up performance evaluation index system;(2) hiring of experts to determine the weights of the performance indicators;(3) to determine the membership function $\mathrm{u}(\mathrm{x})$ of some performance indicators according to historical data and expertise;(4) to obtain the eigen value (actual value) of each factor using data collection or system simulation software;(5) to substitute Eigen values of each factors in the membership function $u(x)$, and to generate a degree of membership;(6) to obtain fuzzy evaluation value $B ;(7)$ to get the best integrated performance results and sort orders of each scheme.

\section{Examples}

\section{1 study}

(1)Kunshan Banknote Paper Mill has a history of producing anti-counterfeiting prper such as banknote more than 30 years, who owns 4 banknote paper producing line with international advanced level of the 1990's. Their products passed the IS09001, IS014001 and OHSAS 18001 International Certification, and they have used ERP systems successfully. We separately studied the production performance before and after the implementation of MES in the enterprise, which do a more favorable evaluation of the effect of MES.

(2)Shandong Huatai Paper Group is a large paper company in China, which applied the Enterprise Resource Planning (ERP) system early and achieved excellent effect. Huatai is one of a few paper-making enterprises whose construction of enterprise information is very prominent. They developed part of MES system in collaboration with Shandong University, Northwestern Polytechnical University and University of Petroleum (East China). The reason why we studied them is that it has a representation in the paper industry.

\subsection{Calculation}

\subsubsection{Hiring of experts and scoring each indicator}

We use AHP to calculate the weight vector set A of indicator layer. So:

$\mathrm{A}=\{0.061,0.045,0.095,0.104,0.14,0.093,0.117,0.073,0.078,0.039,0.024,0.017,0.031,0.029,0.054\}$

\subsubsection{Determine the evaluation set}

We determine the production performance evaluation level as verty good, good, mediocre and bad, which corresponds to level $1,2,3,4$ respectively.

In this evaluation system there are qualitative indicators and quantitative indicators.

Adopting expert scoring method to generate the degree of membership of qualitative indicators, the group of experts give scores to the performanc of each indication of evaluation object based on a ten-point system, then generate the degree of membership dividing the score by 10 .

We adopt membership functio of fuzzy math to generate the degree of membership of quantitative indicators. Then we take "program completion rate" of the indicators for example to calculate the degree of membership of quantitative indicators.

4.2.3 Determine the membership function

We make $4^{\text {th }}$ level membership function of 4 classes for each quantitative indicator with higher or lower semi-trapezoidal method. Taking "program completion rate" of the indicators for example, higher semi-trapezoidal method are suitable for "program completion rate" according to industry standards and previous production experience $4^{\text {th }}$ level membership function of 4 classes are as follows. 


$$
\begin{aligned}
& \mu_{1}(x)_{1}= \begin{cases}0 & x \leq 0.83 \\
(x-0.83) / 0.16 & 0.83<x<0.99 \\
1 & x \geq 0.99\end{cases} \\
& \mu_{1}(x)_{2}= \begin{cases}x-0.7 & 0.7<x<0.8 \\
(0.9-x) / 0.1 & 0.8<x<0.9 \\
0 & x \leq 0.7, x \geq 0.9\end{cases} \\
& \mu_{1}(x)_{3}= \begin{cases}x-0.5 & 0.5<x<0.68 \\
(x-0.68) / 0.13 & 0.68<x<0.81 \\
0 & x \leq 0.5, x \geq 0.81\end{cases} \\
& \mu_{1}(x)_{4}= \begin{cases}0 & x>0.6 \\
(0.6-x) / 0.3 & 0.3<x<0.6 \\
1 & x \leq 0.3\end{cases}
\end{aligned}
$$

4.2.4 Obtain the eigenvalues of various indicators(measured value)

According to statistics of production management of Kunshan Banknote Paper Mill and analysis of report forms of Shandong Huatai Paper Group combined with expert interviews, we obtained data sheet of three objects in the following tables(table 1).

4.2.5 Substitute the eigenvalues(measured value) in the membership function to generate the degree of membership

We substitute the Program completion rate(C5) of Kunshan Banknote Paper Mill which is 0.841 into membership function $\mu_{1}(x), \mu_{2}(x), \mu_{3}(x), \mu_{4}(x)$ respectively, then generate a degree of membership $r_{5 j}=\{0.538,0.462,0,0\}, j=1,2,3,4$.

In the same way, we can get the result of evaluating each indicator of three objects using membership degree, then obtain a $10 \times 4$ fuzzy evaluation matrix. After determining the degree of membership of all qualitative and quantitative indicators, we have to normalize the degree of membership. The evaluation results of Kunshan Banknote Paper Mill (after the application of MES) are in table 2. And we omit the fuzzy evaluation matrixs of the other 2 objects.

4.2.6 The table of obtain the best production performance evaluation(table 3)

\subsection{Conclusion}

(1)Based on the "maximum membership grade principle" in fuzzy comprehensive evaluation ${ }_{2}$ performance evaluation of three objects are in table 4. MES production performance of Huatai Group reached the "very good" level, which received the highest rating of the three objects. This showed that the application and design of MES system were indeed at the leading level. The effect of production performance of Kunshan Banknote Paper Mill after the application of MES was better than before. Therefore, the effect of production performance of Kunshan Banknote Paper Mill after the application of current MES is notable judging from the results of the evaluation. They certainly exist a gap with the advanced domestic enterprises.

(2) In order to assess the conclusions scientifically, accurately and in time, we should pay attention to the following points: to begin with, experts should be authoritative and representative, what's more, Implementation dynamic management should be implemented, that is the evaluation system need periodic assessment, indicator system and the weight should be adjusted timely as well.

\section{References}

J. Sarkis and R.P. Sundarraj. (2005). "Evaluation of Enterprise Information Technologies: A Decision Model for High-Level Consideration of Strategic and Operational Issues",J. IEEE Trans, on Systems, Man, and Cybernetics-Part C Vol., Issue 99, pp.1-14.

J.S.Dyer, (1999). "Remarks on the Analytic Hierarchy Process”, J. Manage. Sci. , vol.36, no.3, pp.249-268.

Li, Enke, Ma, Yuxiang. (2000). "Fuzzy and Analytic Hierarchy Process Models for Comprehensive Evaluation of Information Systems",J. Journal of The China Society for Scientific and Technical Information, Vol.19, No.2, April,pp 181-186. 
Li, Minghui, Wang, Mengxiao, Hu, Nanjiang. (2006). “Application of MES in Papermaking Industry”,J. Transactions of China Pulp and Paper, Vol.21,No.4,pp 94-96.

Liu, Tieming, Xong, Gang, Shen, Judong, et al. (2000). "Research on the Application of CIMS in a Modern Pulp\& Paper Industry",J. Industrial Instrumentation \& Automation, No.3,pp 3-6.

MES Software Evaluation / Selection, MESA international, White Paper No.4, 1996.

Qi, Ershi, Li, Gang, Song, Ninghua. (2006). "Evaluation Methods of MIE Implementation Ability Analysis and Application”, J. JOURNAL OF TIANJIN UNIVERSITY (SOCIALS CIENCES), Vol.8,No.2,Mar,pp 98-102.

S.Schenkerman, (1994). “Avoiding Rank Reversal in AHP Decision-support Models",J. Eur.J.Oper.Res., vol.74, pp.407-419.

Sun, Chunlei. (2004). "Evaluation Method of Core Competence of Pulp\&Paper Enterprise",J. China Pulp \& Paper,Vo1.23,No.1,pp 53-56.

Tao, Qing, Zheng, Wentang. (2002). "Mathematical Moder's Building for Valuation of Tenders of Project Items", $J$. Application of statistics and management, Vol.21, No.6,Dec,pp 37-41.

The Benefits of MES: A Report from the Field, MESA international, White Paper No.1,May, 1997.

Table 1. Data sheet of three study indicators

\begin{tabular}{|c|c|c|c|}
\hline indicator & $\begin{array}{l}\text { Huatai } \\
\text { Group }\end{array}$ & $\begin{array}{l}\text { Kunshan Banknote Paper Mill } \\
\text { (after the application of MES) }\end{array}$ & $\begin{array}{l}\text { Kunshan Banknote Paper Mill } \\
\text { (before the application of MES) }\end{array}$ \\
\hline rejection rate $(\mathrm{C} 3)$ & 0.012 & 0.018 & 0.024 \\
\hline $\begin{array}{l}\text { qualification rate of first } \\
\text { acceptance check }(\mathrm{C} 4)\end{array}$ & 0.982 & 0.985 & 0.920 \\
\hline program completion rate(C5) & 0.867 & 0.841 & 0.812 \\
\hline $\begin{array}{l}\text { the rate of balanced } \\
\text { production }(\mathrm{C} 6)\end{array}$ & 0.743 & 0.704 & 0.658 \\
\hline order fulfilment rate(C7) & 0.941 & 0.978 & 0.969 \\
\hline $\begin{array}{l}\text { average circulation time of } \\
\text { equipments (C9) }\end{array}$ & 0.769 & 0.742 & 0.631 \\
\hline resource utilization rate $(\mathrm{C} 8)$ & 0.725 & 0.606 & 0.549 \\
\hline equipment failure rate(C10) & 0.264 & 0.372 & 0.367 \\
\hline $\begin{array}{l}\text { materials } \quad \text { consumption } \\
\operatorname{rate}(\mathrm{C} 11)\end{array}$ & 0.146 & 0.179 & 0.233 \\
\hline
\end{tabular}


Table 2. Evaluation matrix of Kunshan Banknote Paper Mill (after the application of MES)

\begin{tabular}{lllll}
\hline \multirow{2}{*}{ Indicator } & rating scale & & & \\
\cline { 2 - 5 } C1 & verty good & good & 0 & bad \\
C2 & 0.7 & 0.3 & 0.1 & 0 \\
C3 & 0.7 & 0.2 & 0 & 0 \\
C4 & 0.634 & 0.366 & 0 & 0 \\
C5 & 0.475 & 0.525 & 0 & 0 \\
C6 & 0.538 & 0.462 & 0 & 0 \\
C7 & 0.725 & 0.275 & 0 & 0 \\
C8 & 0.593 & 0.407 & 0.247 & 0 \\
C9 & 0 & 0.753 & 0 & 0 \\
C10 & 0.409 & 0.569 & 0 \\
C11 & 0.591 & 0.431 & 0.372 & 0 \\
C12 & 0 & 0.628 & 0 & 0 \\
C13 & 0 & 0.4 & 0.4 & 0.1 \\
C14 & 0.6 & 0.3 & 0.2 & 0.1 \\
C15 & 0.2 & 0.2 & 0.2 & 0 \\
\hline
\end{tabular}

NOTE: evaluating C1,C2 and C12 adopting expert scoring method; evaluating C5 C11 adopting fuzzy evaluation method

Table 3. The able of Fuzzy Comprehensive Evaluation of MES production performance

\begin{tabular}{ll}
\hline object & Fuzzy Evaluation Value B \\
\hline $\begin{array}{l}\text { Huatai Group } \\
\text { Kunshan Banknote Paper Mill (after the application of }\end{array}$ & $(0.480,0.436,0.084,0)$ \\
MES) & \\
Kunshan Banknote Paper Mill (before the application of & $(0.230,0.248,0.346,0.176)$ \\
MES) & \\
\hline
\end{tabular}

Table 4. production system performance level

\begin{tabular}{ll}
\hline sort & object \\
\hline vry good & Huatai Group \\
good & Kunshan Banknote Paper Mill (after the application of MES) \\
mediocre & Kunshan Banknote Paper Mill (before the application of MES) \\
bad & $/$ \\
\hline
\end{tabular}


Target layer

Criteria layer

Indicator layer

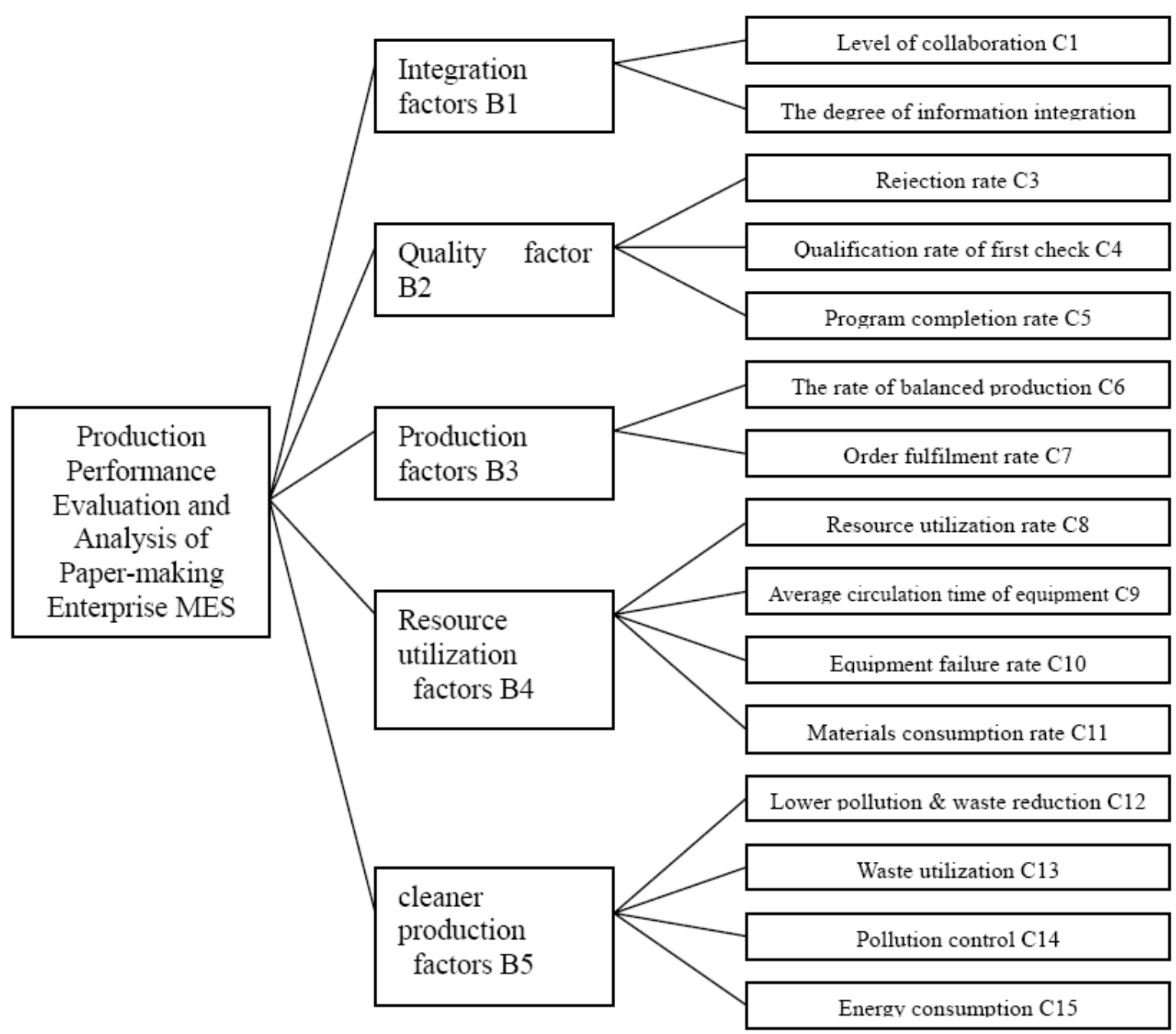

Figure 1. Evaluation model index system 